\title{
Coptis chinensis and Myrobalan (Terminalia chebula) Can Synergistically Inhibit Inflammatory Response In Vitro and In Vivo
}

\author{
Enhui Cui, Xiaoyan Zhi, Ying Chen, Yuanyuan Gao, Yunpeng Fan, Weimin Zhang, \\ Wuren Ma, Weifeng Hou, Chao Guo, and Xiaoping Song \\ College of Veterinary Medicine, Northwest A\&F University, Yangling, Shaanxi 712100, China \\ Correspondence should be addressed to Yunpeng Fan; ypfan@nwsuaf.edu.cn and Xiaoping Song; sxpxbnl@163.com
}

Received 9 October 2014; Revised 26 November 2014; Accepted 27 November 2014; Published 18 December 2014

Academic Editor: Krishnadas Nandakumar

Copyright (C) 2014 Enhui Cui et al. This is an open access article distributed under the Creative Commons Attribution License, which permits unrestricted use, distribution, and reproduction in any medium, provided the original work is properly cited.

Objectives. To investigate the anti-inflammatory effect of Coptis chinensis plus myrobalan (CM) in vitro and in vivo. Methods. The inflammation in mouse peritoneal macrophages was induced by lipopolysaccharide (LPS). Animal models were established by using ear swelling and paw edema of mouse induced by xylene and formaldehyde, respectively. In vitro, cytotoxicity, the phagocytosis of macrophages, the levels of nitric oxide (NO), induced nitric oxide synthase (iNOS), tumor necrosis factor- $\alpha$ (TNF- $\alpha$ ), and interleukin-6 (IL-6) in cell supernatant were detected. In vivo, swelling rate and edema inhibitory rate of ear and paw were observed using CM-treated mice. Results. At $150-18.75 \mu \mathrm{g} \cdot \mathrm{mL}^{-1}, \mathrm{CM}$ had no cytotoxicity and could significantly promote the growth and the phagocytosis of macrophages and inhibit the overproduction of NO, iNOS, TNF- $\alpha$, and IL- 6 in macrophages induced by LPS. In vivo, pretreatment with $\mathrm{CM}$, the ear swelling, and paw edema of mice could be significantly inhibited in a dose-dependent manner, and the antiedema effect of CM at high dose was better than dexamethasone. Conclusion. Our results demonstrated that Coptis chinensis and myrobalan possessed synergistically anti-inflammatory activities in vitro and in vivo, which indicated that CM had therapeutic potential for the prevention and treatment of inflammation-mediated diseases.

\section{Introduction}

Inflammation is a physiological process of body that initiates the response to tissue damage or pathogen infection and is always accompanied by the symptoms of redness, swelling, heat, and hyperalgesia $[1,2]$. Inflammation includes the participation of various cell types expressing and reacting to a variety of mediators along a precise sequence of events [3]. Inflammation response plays an important role in host survival. Usually, it is activated by inflammatory mediators, such as chemokines and cytokines characterized by recruiting leukocytes to the damage parts [4]. However, the excessive inflammatory mediators participate in many diseases, such as bowel diseases, arthritis, allergic rhinitis, atopic dermatitis, and diverse neurodegenerative diseases $[5,6]$. Besides, allergic mediators including histamine, cytokines, and arachidonic acid derivatives could provoke acute and chronic inflammatory responses [7]. Therefore, regulating the production of inflammatory mediator in tissues is very important to the cure of inflammation.

Macrophages are the first defense line of the immune system against pathogen. Increasing evidences indicate that activated macrophages play an important role in inflammatory response through producing various inflammatory factors, such as tumour necrosis factor- $\alpha$ (TNF- $\alpha$ ), interleukin-6 (IL$6)$, and nitric oxide (NO) $[8,9]$, which play an important part in the invasion and spread of pathogens in the organism [10]. However, macrophages possess double performance. If macrophages have been in activated state, it could release excessive inflammatory factors, which will injure tissues and cause inflammatory response [11]. Therefore, it is very important to search some drugs for maintaining the balance of immune system though regulating the activity of macrophages and eliminating the inflammatory reaction. Modern pharmacology experiments suggest that inhibiting the inflammatory factors released by macrophages has 
become the main objective for studying anti-inflammatory drugs [12].

At present, natural product from plant is a promising source for treating the inflammation and allergic reactions $[13,14]$. Based on this context, plant-related compounds or extracts can be used for the treatment of inflammatory diseases and development of new anti-inflammatory drugs. Coptis chinensis, a member of Ranunculaceae family, derives from the dried rhizome of Coptis chinensis Franch., Coptis deltoidea C. Y. Cheng et Hsiao, or Coptis teeta Wall. It is a widely used herb in traditional Chinese medicine and attracts much attention because of its multiple pharmacological effects, such as antibacterial, antiviral, anticancer, and antioxidative effects [15]. Berberine is the major active constituent extracted from Coptis chinensis [16]. Myrobalan (family Combretaceae) derives from the dried fruits of Terminalia chebula Retz. It is recorded in Illustrated Materia Medica; its use could be dated back to more than 1000 years ago. It is the most commonly used in Tibetan Medicine and is called the king of the Tibetan Medicine. Now, myrobalan has been extensively used in Southeast Asia [17]. Tannin, as main active ingredient of myrobalan, has been shown to possess various beneficial pharmacological activities, such as antioxidation, antibacterial, and antivirus activities [18].

After infecting bacteria, the organism often shows inflammatory response. Previous experiments have proved that the prescription, Coptis chinensis plus myrobalan (CM), had stronger antibacterial effect in comparison with the single ones [19]. But we did not know whether it possessed a better anti-inflammatory effect. Therefore, in this study, we investigate the anti-inflammatory activity of $\mathrm{CM}$ in vitro and in vivo. The aim is to offer theoretical evidence for exploiting new-type anti-inflammatory drugs on curing the inflammation caused by bacteria.

\section{Materials and Methods}

2.1. Preparation of CM. Coptis chinensis was provided by Anhui Huafeng Chinese Medicine Technology Co., Ltd. Myrobalan was purchased from Hubei Jusheng Science and Technology Co., Ltd. Plant materials (100 g) were extracted with $800 \mathrm{~mL}$ of boiling distilled water for $3 \mathrm{~h}$ and filtered through a filter paper twice. All the extracts were combined together and centrifuged at $5000 \times \mathrm{g}$ for $30 \mathrm{~min}$. The supernatant was filtered through a $0.22 \mu \mathrm{m}$ membrane, and the filtrate was then concentrated to $100 \mathrm{~mL}$ by evaporation in vacuum at $70^{\circ} \mathrm{C}$. Finally, the prescription, Coptis chinensis plus myrobalan $(\mathrm{CM})$, was obtained. The concentration of $\mathrm{CM}$ was that each $1 \mathrm{~mL}$ contained $1 \mathrm{~g}$ crude starting materials. In vitro, it was diluted into eleven working concentrations $\left(20 \mathrm{mg} \cdot \mathrm{mL}^{-1}-19.82 \mu \mathrm{g} \cdot \mathrm{mL}^{-1}\right)$ in twofold serial dilution with RPMI-1640 containing 10\% fetal bovine serum, sterilized, and stored at $4^{\circ} \mathrm{C}$. In vivo, it was diluted into high $\left(800 \mathrm{mg} \cdot \mathrm{mL}^{-1}\right)$, medium $\left(400 \mathrm{mg} \cdot \mathrm{mL}^{-1}\right)$, and low $\left(200 \mathrm{mg} \cdot \mathrm{mL}^{-1}\right)$ concentrations with deionized water, sterilized, and stored at $4^{\circ} \mathrm{C}$. The endotoxin amount was up to the standard of Chinese Veterinary Pharmacopeia (less than $0.5 \mathrm{EU} \cdot \mathrm{mL}^{-1}$ ).
2.2. Chemicals and Reagents. Dexamethasone sodium phosphate injection (number 20130722) was purchased from Sichuan Taixin Animal Pharmaceutical Co., Ltd. RPMI-1640 (GIBCO) with the supplement of $100 \mathrm{IU} \cdot \mathrm{mL}^{-1}$ benzylpenicillin, $100 \mathrm{IU} \cdot \mathrm{mL}^{-1}$ streptomycin, and $10 \%$ fetal bovine serum (Hyclone, USA) was used for washing and resuspending cells, diluting mitogen, and culturing the cells. The 3(4,5-dimethylthiazol-2-yl)-2,5-diphenyltetrazolium bromide (MTT, American Co.) was dissolved into $5 \mathrm{mg} \cdot \mathrm{mL}^{-1}$ with calcium and magnesium-free phosphate-buffered saline (PBS, $\mathrm{pH}$ 7.2). Lipopolysaccharide (LPS, Sigma, number L2880) was dissolved into $2 \mu \mathrm{g} \cdot \mathrm{mL}^{-1}$ with RPMI-1640. These reagents were filtered through a $0.22 \mu \mathrm{m}$ millipore membrane filter. Dimethyl sulfoxide (DMSO) was produced by Kemiou Institute of Chemical Engineering in Tianjin, China. Xylene, formaldehyde, and other chemicals used in experiments were of analytical grade.

2.3. Analysis of the Berberine in Extract. High performance liquid chromatography (HPLC) analysis was performed using an Agilent Technologies 1200 Series, with a PDA detector and an automatic injector. The column employed was a Zorbax SB-18, $250 \times 4.6 \mathrm{~mm}$ and $5 \mu \mathrm{m}$ particle size. The column temperature was set at $30^{\circ} \mathrm{C}$. The mobile phase was a mixture of $0.05 \mathrm{moL} \cdot \mathrm{L}^{-1} \mathrm{KH}_{2} \mathrm{PO} 4$ in water and acetonitrile $(50: 50, \mathrm{v} / \mathrm{v})$ at a flow rate of $1.0 \mathrm{~mL} / \mathrm{min}$. The monitoring wavelength was chosen at $345 \mathrm{~nm}$, and the injection volume was $10 \mu \mathrm{L}$. The identification of the compounds was performed by comparison of the retention time and spectrum. The peak area of analyte was used for quantification.

\subsection{Anti-Inflammatory Activity of CM In Vitro}

2.4.1. Peritoneal Macrophages Culture. Macrophages were isolated by peritoneal lavage method with minor modifications according to previous report [20]. In brief, ICR mice (8 weeks old) were injected intraperitoneally with $1 \mathrm{~mL}$ of $6 \%$ starch-broth medium. Two days later, the peritoneal cavity was washed with $20 \mathrm{~mL}$ of PBS, and the macrophages in peritoneal fluid were collected. After centrifugation at $2000 \mathrm{rpm}$ for $10 \mathrm{~min}$, the cells were collected and washed twice with PBS. Then the cells were resuspended in RPMI-1640 and seeded in culture plates $\left(1 \times 10^{6}\right.$ cells $\left.\cdot \mathrm{mL}^{-1}\right)$ for $2 \mathrm{~h}$ at $37.5^{\circ} \mathrm{C}$ in a humid atmosphere with $5 \% \mathrm{CO}_{2}$. Nonadherent cells were removed by light washing twice with RPMI-1640, and the adherent cells were macrophages. Cell viability measured by trypan blue exclusive assay was never below $95 \%$.

2.4.2. Cytotoxicity Analysis. CM was diluted with maintenance medium into 11 concentrations from $20 \mathrm{mg} \cdot \mathrm{mL}^{-1}$ to $19.82 \mu \mathrm{g} \cdot \mathrm{mL}^{-1}$ for the test. Then CM at series of concentrations was added into the plates with splenocytes, $100 \mu \mathrm{L} /$ well, and four wells each concentration. After a culture for $44 \mathrm{~h}$, $20 \mu \mathrm{L}$ MTT was added into each well and incubated at $37.5^{\circ} \mathrm{C}$ in a humid atmosphere of $5 \% \mathrm{CO}_{2}$ for $4 \mathrm{~h}$, the supernatant was removed, and $100 \mu \mathrm{L}$ of DMSO was added. The plates were shaken for $5 \mathrm{~min}$ to dissolve the crystals completely. The absorbance at $490 \mathrm{~nm}\left(A_{490}\right.$ value $)$ of each well was 
measured by microliter enzyme-linked immunosorbent assay reader. Cell viability was calculated by the following equation: cell viability $(\%)=\mathrm{Int}_{d} / \mathrm{Int}_{\text {control }} \times 100$, where $\mathrm{Int}_{d}:$ the

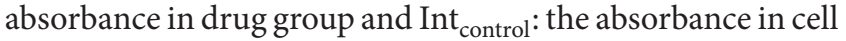
control group [21].

\subsubsection{Phagocytic Assay by Neutral Red Method. The phago-} cytosis of macrophages was measured by neutral red uptake [22]. After being cultured with CM or LPS for $48 \mathrm{~h}, 100 \mu \mathrm{L}$ of neutral red solution $(0.075 \%$, w/w $)$ was added and incubated for $4 \mathrm{~h}$. After discarding supernatant, the cells were washed with PBS twice to remove the neutral red which was not phagocytized by macrophages. Then DMSO (100 $\mu \mathrm{L} /$ well) was added to lyse macrophages. The absorbance at $490 \mathrm{~nm}$ was assayed by a microplate reader.

2.4.4. Measurement of NO. The NO was measured according to the previous description [23]. Cells were pretreated with $2 \mu \mathrm{g} \cdot \mathrm{mL}^{-1}$ of LPS for $2 \mathrm{~h}$ and then were cultured with CM at four concentrations $\left(300-37.5 \mu \mathrm{g} \cdot \mathrm{mL}^{-1}\right)$ for $48 \mathrm{~h}$. Finally, $100 \mu \mathrm{L} /$ well of culture medium was incubated with equal volume of Griess reagent ( $1 \%$ sulfanilamide, $0.1 \%$ naphthyl ethylenediamine dihydrochloride, and $2.5 \%$ phosphoric acid) for $10 \mathrm{~min}$. NO was determined at $550 \mathrm{~nm}$ using ultraviolet spectrophotometer.

2.4.5. Determination of iNOS, TNF- $\alpha$, and IL-6 Levels. The peritoneal macrophages were inoculated into 96-well culture plates. Cells were pretreated with $2 \mu \mathrm{g} \cdot \mathrm{mL}^{-1}$ of LPS for $2 \mathrm{~h}$. After being treated with drugs for $44 \mathrm{~h}$, the plates were centrifuged at $1000 \times \mathrm{g}$ for $10 \mathrm{~min}$, and the supernatant was collected for determining the contents of induced nitric oxide synthase (iNOS), TNF- $\alpha$, and IL- 6 by ELISA kit (Biosamite Biotechnology Co. Ltd., Shanghai, China), respectively, according to the manufacturer's instructions.

\subsection{Anti-Inflammatory Activity of CM In Vivo}

2.5.1. Animals. ICR mice (8 weeks old) weighing $20-25 \mathrm{~g}$ were purchased from the Fourth Military Medical University Laboratory Animal Center Co. Ltd. (Shanxi, China). They were housed in an environmentally controlled animal facility maintained at $22 \pm 2^{\circ} \mathrm{C}$ with a $12 / 12 \mathrm{~h}$ light/dark cycle. Feed and water were supplied ad libitum. All procedures related to the animals and their care conformed to the internationally accepted principles as found in the Guidelines for Keeping Experimental Animals issued by the Government of China.

\subsubsection{Xylene Induced Ear Swelling in Mice. Forty ICR mice} ( 8 weeks old) were randomly divided into four groups. The mice in three experimental groups were treated, respectively, with $1.0 \mathrm{~mL}$ of $\mathrm{CM}$ at high $\left(800 \mathrm{mg} \cdot \mathrm{mL}^{-1}\right)$, medium $\left(400 \mathrm{mg} \cdot \mathrm{mL}^{-1}\right)$, and low $\left(200 \mathrm{mg} \cdot \mathrm{mL}^{-1}\right)$ dose by gavage, in dexamethasone and blank control (BC) group, $1.0 \mathrm{~mL}$ of dexamethasone $\left(0.6 \mathrm{~g} \cdot \mathrm{kg}^{-1}\right)$, and physiological saline, once a day for 3 successive days. $30 \mathrm{~min}$ after the last drug administration, a total volume of $0.05 \mathrm{~mL}$ xylene was applied to the anterior and posterior surfaces of the right ear. The left ear was used as control. $1 \mathrm{~h}$ later, all mice were euthanized by cervical dislocation and both ears were removed. Circular sections with a diameter of $9 \mathrm{~mm}$ were taken using a cork borer and weighed. Edema $\left(\Delta_{W}\right)$ is calculated as follows: $\Delta_{W}=W_{R}-W_{L}$, where $W_{R}$ is the right ear sample weight (mg) and $W_{L}$ is left ear weight (mg) of the same mouse. Swelling rate and edema inhibitory rate were calculated according to the following formula [24]: swelling rate $(\%)=\Delta_{W} / W_{L}$; inhibitory rate $(\%)=\left(W_{\text {blank control }}-W_{\text {treated }}\right) / W_{\text {blank control }} \times$ $100 \%$.

2.5.3. Formaldehyde Induced Paw Edema in Mice. Forty ICR mice ( 8 weeks old) were randomly divided into four groups. The mice in three experimental groups were treated, respectively, with $1.0 \mathrm{~mL}$ of $\mathrm{CM}$ at high $\left(800 \mathrm{mg} \cdot \mathrm{mL}^{-1}\right)$, medium $\left(400 \mathrm{mg} \cdot \mathrm{mL}^{-1}\right)$, and low $\left(200 \mathrm{mg} \cdot \mathrm{mL}^{-1}\right)$ dose by gavage, in dexamethasone and blank control (BC) group, $1.0 \mathrm{~mL}$ of dexamethasone $\left(0.6 \mathrm{~g} \cdot \mathrm{kg}^{-1}\right)$, and physiological saline, once a day for 3 successive days. $30 \mathrm{~min}$ after the last drug administration, $0.05 \mathrm{~mL}$ of formaldehyde was injected into the subplantar area of the right hind paw. The thickness $(\mathrm{mm})$ of the paw was measured before the injection of formaldehyde and then at $3 \mathrm{~h}$ after formaldehyde injection. Edema $\left(\Delta_{T}\right)$ is calculated as follows: $\Delta_{T}=T_{t}-T_{o}$, where $T_{t}$ is the right hind paw thickness ( $\mathrm{mm}$ ) after formaldehyde injection and $T_{o}$ is the right hind paw thickness $(\mathrm{mm})$ prior to subplantar injection. Swelling rate and edema inhibitory rate were calculated according to the following formula: swelling rate $(\%)=\Delta_{T} / T_{o}$; inhibitory rate $(\%)=\left(\Delta_{T \text { blank control }}-\right.$ $\left.\Delta_{T \text { treated }}\right) / \Delta_{T \text { blank control }} \times 100 \%$ [25] (see Figure 9).

2.6. Statistical Analysis. Data are expressed as the mean \pm S.D. Duncan's multiple range test was used to determine the differences among groups with the software SPSS 19.0. $\chi^{2}$-test was used to analyze the difference of the inhibitive rate of edema. Significant differences were considered as $P<0.05$.

\section{Results}

3.1. Characterization of Extracts from CM by HPLC. Figure 1 shows the base peak chromatogram extract from CM by HPLC. The results showed that berberine standard $\left(20 \mu \mathrm{g} \cdot \mathrm{mL}^{-1}\right)$ only has one peak and the retention time was $15.374 \mathrm{~min}$ (Figure 1(a)). At the same location, the extract of $\mathrm{CM}$ also had a peak, and the peak possessed a good separating degree (Figure 1(b)). This peak area represented the content of berberine in CM. After being calculated, the content of berberine in $\mathrm{CM}$ was $35.8 \mathrm{mg} \cdot \mathrm{mL}^{-1}$.

3.2. Cytotoxicity. The cell viabilities of every concentration are shown in Figure 1. The cell viabilities of CM at $4800-$ $600 \mu \mathrm{g} \cdot \mathrm{mL}^{-1}$ were significantly smaller than that in cell control (CC) group $(P<0.05)$, which indicated that $\mathrm{CM}$ had cytotoxicity and could inhibit the growth of macrophages at these concentrations. The cell viabilities at 150, 4.7, 2.35, and $1.175 \mu \mathrm{g} \cdot \mathrm{mL}^{-1}$ were all slightly larger than that in CC group 


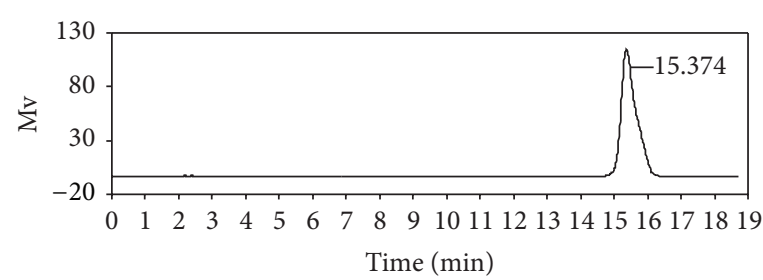

(a)

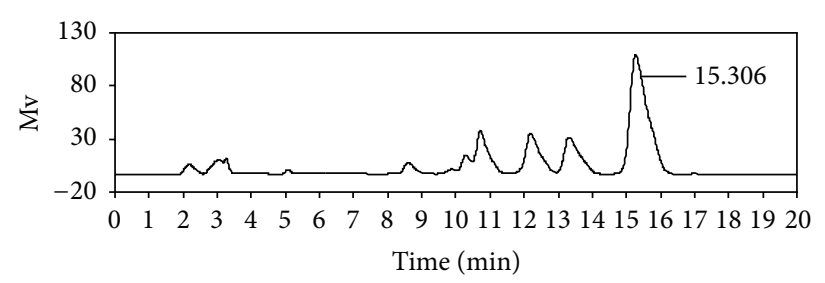

(b)

FiguRE 1: Chromatogram of berberine obtained at $345 \mathrm{~nm}$. (a) Berberine standard; (b) the extract of CM.

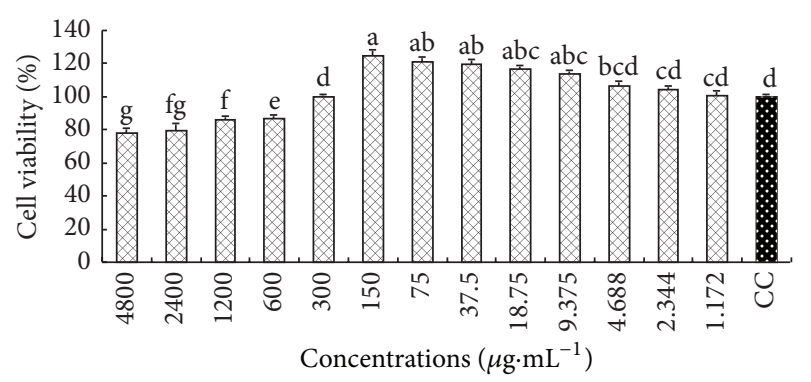

Figure 2: The cell viability of macrophages incubated with CM. ${ }^{\mathrm{a}-\mathrm{g}}$ Bars without the same superscripts differ significantly $(P<0.05)$.

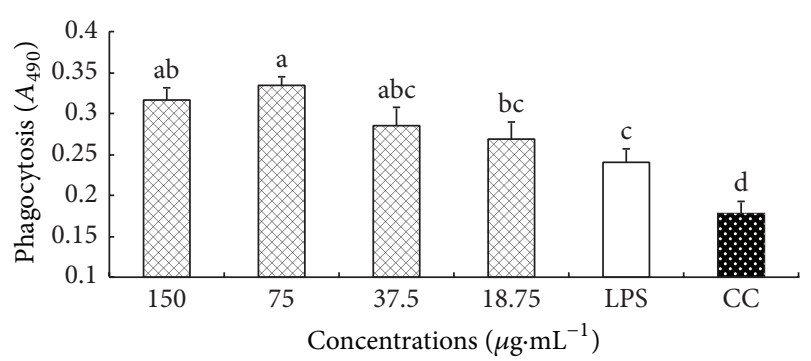

FIGURE 3: The effect of CM on phagocytosis of macrophages. ${ }^{\mathrm{a}-\mathrm{d}} \mathrm{Bars}$ without the same superscripts differ significantly $(P<0.05)$.

$(P>0.05)$, which indicated that $\mathrm{CM}$ had no cytotoxicity and could not promote cell growth at these concentrations, so $150 \mu \mathrm{g} \cdot \mathrm{mL}^{-1}$ could be considered as maximal safe concentration of CM. The cell viabilities of CM at 150$9.375 \mu \mathrm{g} \cdot \mathrm{mL}^{-1}$ were significantly larger than that in CC group $(P<0.5)$, which indicated that CM could promote the growth of macrophages at these concentrations. In order to investigate the efficacy of $\mathrm{CM}$, therefore, the concentrations of CM were supposed to be $150,75,37.5$, and $18.75 \mu \mathrm{g} \cdot \mathrm{mL}^{-1}$ for determining its anti-inflammatory activity on macrophages in vitro.

3.3. Effect of CM on Phagocytosis of Neutral Red. The effect of $\mathrm{CM}$ on phagocytosis of neutral red is illustrated in Figure 2. The $A_{490}$ values in LPS and CM groups at $150-18.75 \mu \mathrm{g} \cdot \mathrm{mL}^{-1}$ were significantly higher than CC group $(P<0.05)$. At four concentrations, the $A_{490}$ values in CM group were all higher than that in LPS group, and the differences were significant at 312.5 and $156.25 \mu \mathrm{g} \cdot \mathrm{mL}^{-1}(P<0.05)$.

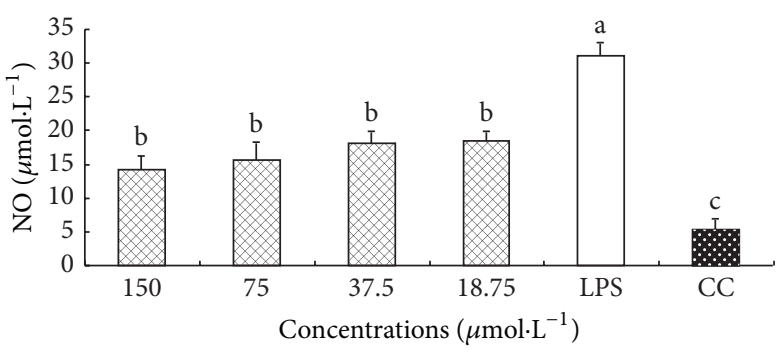

FIgURE 4: Effect of CM on the production of NO. ${ }^{\mathrm{a}-\mathrm{c}}$ Bars without the same superscripts differ significantly $(P<0.05)$.

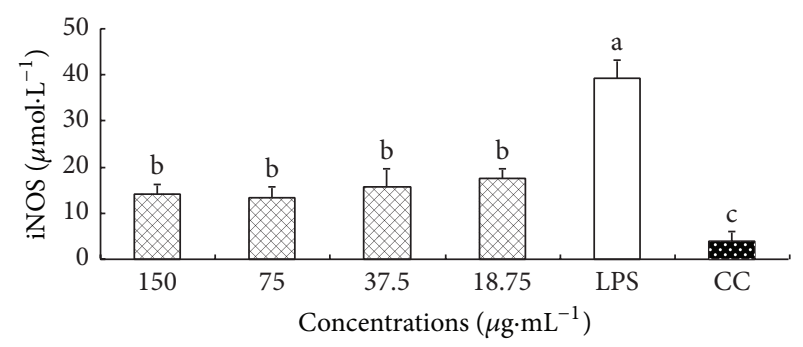

FIGURE 5: Effect of CM on the production of iNOS. ${ }^{a-c}$ Bars without the same superscripts differ significantly $(P<0.05)$.

3.4. Effect of CM on the Production of NO. The effect of $\mathrm{CM}$ on the production of NO from macrophages is shown in Figure 3. The level of NO in LPS group was significantly higher than that in CC group $(P<0.05)$, which indicated that LPS could stimulate macrophages to produce NO. At $150-18.75 \mu \mathrm{g} \cdot \mathrm{mL}^{-1}$, the levels of NO in CM group were all significantly lower than that in LPS group $(P<0.05)$.

3.5. Effect of CM on the Production of iNOS. The effect of $\mathrm{CM}$ on the production of iNOS from macrophages is shown in Figure 4. The level of iNOS in LPS group was significantly higher than that in CC group $(P<0.05)$. At $150-18.75 \mu \mathrm{g} \cdot \mathrm{mL}^{-1}$, the levels of iNOS in CM group were all significantly lower than that in LPS group $(P<0.05)$.

3.6. Effect of CM on TNF- $\alpha$ Secretion. The effect of CM on the secretion of TNF- $\alpha$ from macrophages is shown in Figure 5. The level of TNF- $\alpha$ in LPS group was significantly higher than that in CC group $(P<0.05)$, which indicated that LPS could 


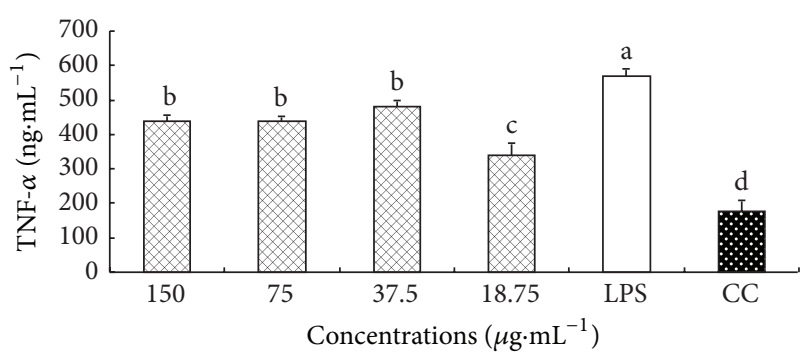

FIGURE 6: Effect of CM on the TNF- $\alpha$ secretion. ${ }^{a-d}$ Bars without the same superscripts differ significantly $(P<0.05)$.

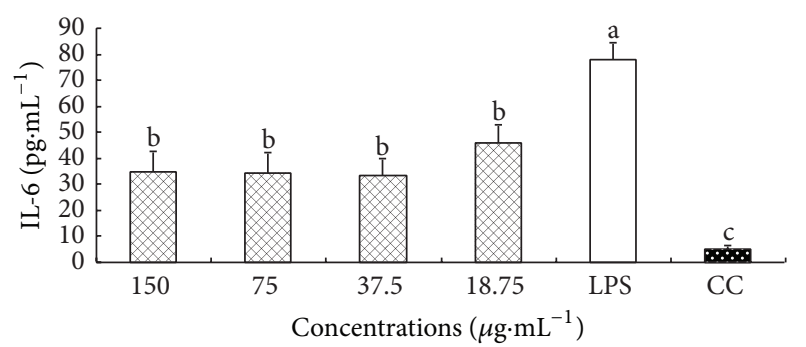

FIgURE 7: Effect of CM on the IL-6 secretion. ${ }^{\mathrm{a}-\mathrm{c}}$ Bars without the same superscripts differ significantly $(P<0.05)$.

stimulate macrophages to secrete inflammatory factor (TNF$\alpha$ ). At $150-18.75 \mu \mathrm{g} \cdot \mathrm{mL}^{-1}$, the levels of TNF- $\alpha$ in CM group were all significantly lower than that in LPS group $(P<0.05)$.

3.7. Effect of CM on IL-6 Secretion. The effect of CM on the secretion of IL-6 from macrophages is shown in Figure 6. The level of IL-6 in LPS group was significantly higher than that in CC group $(P<0.05)$, which indicated that LPS could stimulate macrophages to secrete inflammatory factor (TNF$\alpha)$. At $150-18.75 \mu \mathrm{g} \cdot \mathrm{mL}^{-1}$, the levels of IL-6 in CM group were all significantly lower than that in LPS group $(P<0.05)$.

3.8. Effect of CM on Xylene Induced Ear Swelling in Mice. Figure 7 shows the swelling rate and inhibitory rate of $\mathrm{CM}$ in xylene induced ear swelling in mice. The results demonstrated that the swelling rates of ear in $\mathrm{CM}_{\mathrm{H}}, \mathrm{CM}_{\mathrm{M}}$, $\mathrm{CM}_{\mathrm{L}}$, and dexamethasone groups were significantly lower than that in $\mathrm{BC}$ group $(P<0.05)$. The swelling rate in $\mathrm{CM}_{\mathrm{H}}$ group was the lowest and significantly lower than other groups $(P<0.05)$. The inhibitory rates of ear in $\mathrm{CM}_{\mathrm{H}}, \mathrm{CM}_{\mathrm{M}}$, $\mathrm{CM}_{\mathrm{L}}$, and dexamethasone groups were significantly higher than that in $\mathrm{BC}$ group $(P<0.05)$. The inhibitory rate in $\mathrm{CM}_{\mathrm{H}}$ group was the highest and significantly higher than those in $\mathrm{CM}_{\mathrm{H}}$ and $\mathrm{CM}_{\mathrm{L}}$ groups $(P<0.05)$.

\subsection{Effect of CM on Formaldehyde Induced Paw Edema in} Mice. Figure 8 shows the swelling rate and inhibitory rate of $\mathrm{CM}$ in formaldehyde induced paw edema in mice. The results demonstrated that the swelling rates of paw in $\mathrm{CM}_{\mathrm{H}}, \mathrm{CM}_{\mathrm{M}}$, $\mathrm{CM}_{\mathrm{L}}$, and dexamethasone groups were all lower than that in $\mathrm{BC}$ group; $\mathrm{CM}_{\mathrm{H}}$ group was the lowest and significantly lower than $\mathrm{BC}$ group $(P<0.05)$. The inhibitory rates of paw in $\mathrm{CM}_{\mathrm{H}}, \mathrm{CM}_{\mathrm{M}}, \mathrm{CM}_{\mathrm{L}}$, and dexamethasone groups were all

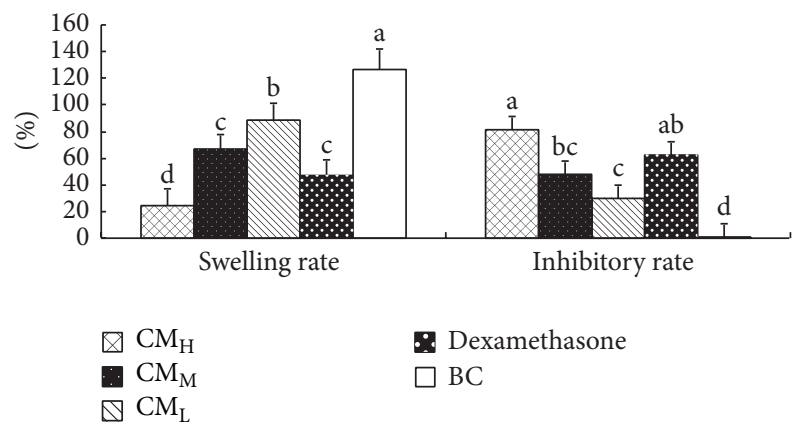

Figure 8: Effect of CM on xylene induced ear swelling in mice. ${ }^{\mathrm{a}-\mathrm{b}}$ Bars without the same superscripts differ significantly $(P<0.05)$. $\mathrm{H}$ : high dose; M: medium dose; L: low dose; BC: blank control.

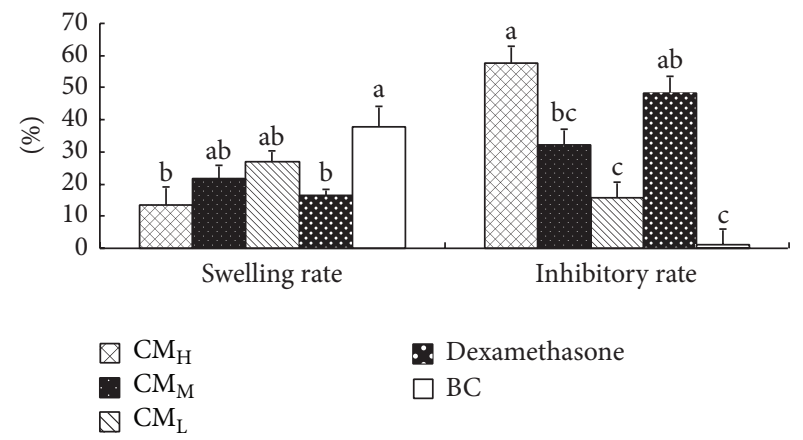

FIGURE 9: Effect of CM on formaldehyde induced paw edema in mice. ${ }^{\mathrm{a}-\mathrm{b}}$ Bars without the same superscripts differ significantly $(P<$ 0.05). H: high dose; M: medium dose; L: low dose; BC: blank control.

higher than that in $\mathrm{BC}$ group; $\mathrm{CM}_{\mathrm{H}}$ group was the highest and significantly higher than those in $\mathrm{CM}_{\mathrm{M}}, \mathrm{CM}_{\mathrm{L}}$, and $\mathrm{BC}$ groups $(P<0.05)$. There was no significant difference between $\mathrm{CM}_{\mathrm{H}}$ and dexamethasone groups $(P>0.05)$.

\section{Discussion}

As an important member of natural immune system, macrophage possesses a variety of physiological functions such as antigen presentation, phagocytosis, and stimulating the secretion of inflammatory mediators, and it plays an important role in regulating inflammatory response [26]. LPS possesses a high activity and is a widespread used infectious agent [27]. At present, LPS is considered as the strongest irritant for activating macrophages. LPS can specifically combine with the receptor proteins on the surface of macrophage when it enters the macrophages, then activating the related genes of cytokine and enzyme, finally inducing and synthetizing plenty of inflammatory cytokines [28]. Therefore, macrophage stimulated by LPS has been used as the effective cellular model to study a new drug on anti-inflammatory action and mechanism in vitro [29]. In the present experiment, the peritoneal macrophages of mouse stimulated with LPS were used to investigate the anti-inflammatory activity of $\mathrm{CM}$. The experimental results showed that the contents of NO, iNOS, TNF- $\alpha$, and IL-6 in LPS group were significantly higher than those in blank 
control group, which indicated that the inflammatory model was established successfully. So this model could be used to evaluate the anti-inflammatory effect of CM.

Phagocytosis is the indispensable step of the immunological defense system. The enhancement of phagocytic function is expected to be applicable for treating microbial infections and cancer, because phagocytes play roles as regulatory and effector cells by phagocytizing pathogenic microorganism and invasive cells (including cancer cells) in immune system [30]. In this study, we detected the phagocytosis activity of CM on macrophages. The experimental results showed that CM could significantly increase the phagocytosis of macrophages, and the effect was significantly higher than LPS. These results suggested that CM could result in the initiation of immune reaction against foreign materials such as pathogens and tumors. Many researches also proved that some traditional Chinese medicines could improve the phagocytosis activity of peritoneal macrophages [31, 32].

Nitric oxide (NO), as an important second messenger molecule in mammalian, participates in various physiological and pathological processes. Appropriate levels of $\mathrm{NO}$ in body are essential in maintaining many normal physiological functions, but excessive NO possesses cytotoxicity and could result in sepsis, inflammation, and carcinogenesis [33]. iNOS is the most important enzyme to catalyse NO after the activation of macrophages [34]. Therefore, it is conducive to estimate the effect of drugs on inhibiting the early inflammatory response through studying the production of $\mathrm{NO}$ and iNOS in macrophages. The experimental results showed that CM could significantly inhibit the release of NO and iNOS in macrophages stimulated by LPS; it suggested that $\mathrm{CM}$ had a better anti-inflammation effect. The reason may be that CM inhibited the level of NO production through suppressing the activity or overexpression of iNOS. Many researches proved that some herb medicines possessed antiinflammatory activity and also could inhibit the release of $\mathrm{NO}$ and iNOS in inflammatory response $[35,36]$.

TNF- $\alpha$ and IL- 6 are the important cytokines in the early pathogenesis of inflammation. In inflammatory response, TNF- $\alpha$ could induce nonspecific immune responses by activating macrophages and stimulating the secretions of other inflammatory cytokines [37]. It is released during the early phase of acute and chronic inflammatory diseases, such as septic shock, rheumatoid arthritis, and other allergic diseases. IL-6, mainly produced by T cells and macrophages, is considered as one kind of markers of the inflammation [36]. At the beginning of the inflammation, IL-6 is expressed in abundance; it is involved in the further development of the inflammatory response and induces the expression of other inflammatory factors. Therefore, IL-6 plays an important role in inflammatory response [9]. In our experiment, CM could significantly reduce the production of TNF- $\alpha$ and IL- 6 in macrophages induced by LPS. It indicated that CM had a better anti-inflammatory effect. The biosynthesis of TNF- $\alpha$ and IL- 6 is regulated and controlled by complex and multiple mechanisms, which mainly includes gene transcription, mRNA turnover, and translation of intracellular signaling of proteins [38]. Therefore, CM with the inhibitory the secretion of TNF- $\alpha$ and IL- 6 might be possible to target these aspects.
Edema is a kind of basic pathological changes at the inflammatory site, and it also is the character of acute inflammation. The effect of anti-inflammatory drug greatly depends on its inhibition degree on edema when it was used in acute inflammation. In this experiment, the animal models including ear swelling and paw edema induced by xylene and formaldehyde, respectively, are used to investigate the anti-inflammatory activity of CM. The model of ear swelling induced by xylene is a classical animal model for assessing the anti-inflammatory activity of drugs, because xylene could stimulate the production of inflammatory mediators such as bradykinin, prostaglandins, and serotonin, which induce ear swelling by promoting vasodilation and increasing vascular permeability [39]. The results showed that CM could dosedependently inhibit the formation of edema induced by xylene, and the effect was better than dexamethasone at high dose. The reason may be that CM interfered with the secretion of the above mediators. As an acute inflammatory model, paw edema induced by formaldehyde is also widely used to evaluate the anti-inflammatory activity of drugs. This process includes three stages [40]. The final stage $(2.5-6 \mathrm{~h})$ is the most important process in the inflammatory response, because it is associated with leukocyte migration into the inflamed site [41]. So we determined the paw edema at $3 \mathrm{~h}$ after injecting formaldehyde. The result indicated that CM played a crucial role in protecting against acute inflammation induced by formaldehyde, and the effect was better than dexamethasone at high dose.

\section{Conclusions}

The results demonstrated that CM had potent anti-inflammatory activity in vitro and in vivo, including promoting the phagocytic function of macrophages, inducing the release of NO, iNOS, TNF- $\alpha$, and IL- 6 by macrophages, and inhibiting the edema of ear and paw in mice. Nevertheless, the mechanism of the effect on macrophages by CM is still unknown; further studies and experiments on the mechanism of CM in vivo are in progress.
Abbreviations
CM: Coptis chinensis plus myrobalan
TNF- $\alpha$ : Tumour necrosis factor- $\alpha$
IL-6: Interleukin-6
NO: $\quad$ Nitric oxide
LPS: Lipopolysaccharide
MTT: 3-(4,5-Dimethylthiazol-2-yl)-2,5- diphenyltetrazolium bromide
PBS: $\quad$ Phosphate buffered saline
DMSO: Dimethyl sulfoxide
iNOS: Induced nitric oxide synthase
BC: Blank control
CC: Cell control.

\section{Conflict of Interests}

The authors declare that there is no conflict of interests regarding the publication of this paper. 


\section{Authors' Contribution}

Enhui Cui and Xiaoyan Zhi contributed equally to this work. They were responsible for protocol designing, recruitment of the patients, and data analysis. Yuanyuan Gao, Ying Chen, and Weimin Zhang were responsible for follow-up and assessment of outcomes and data analysis. Weifeng Hou and Chao Guo were responsible for statistical guidance. Wuren Ma was responsible for designing of rehabilitation protocol and guidance of patients. Yunpeng Fan and Xiaoping Song were responsible for protocol designing and draft editing.

\section{Acknowledgments}

The project was supported by Project funded by Special Fund for Agro-Scientific Research in the Public Interest (Grant no. 201303040) and the National Natural Science Foundation of China (Grant no. 31402240). The authors are grateful to all other staff in the Institute of Traditional Chinese Veterinary Medicine of Northwest A\&F University for their assistance in the experiments.

\section{References}

[1] Y. Lun, H. Xia, Q. Zhang et al., "Anti-inflammatory and immunosuppressive activities of 1,3-dicyclopentyl-1,2,3,6tetrahydropyrimidine-4,5-dicarboxylic acid diethyl ester (ZL-5015)," International Immunopharmacology, vol. 17, no. 2, pp. 168-177, 2013.

[2] A. Mantovani, P. Allavena, A. Sica, and F. Balkwill, "Cancerrelated inflammation," Nature, vol. 454, no. 7203, pp. 436-444, 2008.

[3] N. P. Babu, P. Pandikumar, and S. Ignacimuthu, "Antiinflammatory activity of Albizia lebbeck Benth., an ethnomedicinal plant, in acute and chronic animal models of inflammation," Journal of Ethnopharmacology, vol. 125, no. 2, pp. 356-360, 2009.

[4] S. Talwar, K. Nandakumar, P. G. Nayak et al., "Antiinflammatory activity of Terminalia paniculata bark extract against acute and chronic inflammation in rats," Journal of Ethnopharmacology, vol. 134, no. 2, pp. 323-328, 2011.

[5] B. Kaminska, "MAPK signalling pathways as molecular targets for anti-inflammatory therapy - From molecular mechanisms to therapeutic benefits," Biochimica et Biophysica Acta (BBA)Proteins and Proteomics, vol. 1754, no. 1-2, pp. 253-262, 2005.

[6] T. Mainardi, S. Kapoor, and L. Bielory, "Complementary and alternative medicine: herbs, phytochemicals and vitamins and their immunologic effects," Journal of Allergy and Clinical Immunology, vol. 123, no. 2, pp. 283-294, 2009.

[7] A. M. Gilfillan and C. Tkaczyk, "Integrated signalling pathways for mast-cell activation," Nature Reviews Immunology, vol. 6, no. 3, pp. 218-230, 2006.

[8] T. Lawrence, D. A. Willoughby, and D. W. Gilroy, "Antiinflammatory lipid mediators and insights into the resolution of inflammation," Nature Reviews Immunology, vol. 2, no. 10, pp. 787-795, 2002.

[9] A. Yoshimura, "Signal transduction of inflammatory cytokines and tumor development," Cancer Science, vol. 97, no. 6, pp. 439447, 2006.

[10] S. M. Cardona, J. A. Garcia, and A. E. Cardona, "The fine balance of chemokines during disease: trafficking, inflammation, and homeostasis," Methods in Molecular Biology, vol. 1013, pp. 1-16, 2013.

[11] P. Libby, P. M. Ridker, and A. Maseri, "Inflammation and atherosclerosis," Circulation, vol. 105, no. 9, pp. 1135-1143, 2002.

[12] D. Salvemini, Z.-Q. Wang, M. K. Stern, M. G. Currie, and T. P. Misko, "Peroxynitrite decomposition catalysts: therapeutics for peroxynitrite- mediated pathology," Proceedings of the National Academy of Sciences of the United States of America, vol. 95, no. 5, pp. 2659-2663, 1998.

[13] R. S. Talhouk, C. Karam, S. Fostok, W. El-Jouni, and E. K. Barbour, "Anti-inflammatory bioactivities in plant extracts," Journal of Medicinal Food, vol. 10, no. 1, pp. 1-10, 2007.

[14] J. Lee and L. Bielory, "Complementary and alternative interventions in atopic dermatitis," Immunology and Allergy Clinics of North America, vol. 30, no. 3, pp. 411-424, 2010.

[15] J. M. Kim, H. A. Jung, J. S. Choi, and N. G. Lee, "Identification of anti-inflammatory target genes of Rhizoma coptidis extract in lipopolysaccharide-stimulated RAW264.7 murine macrophage-like cells," Journal of Ethnopharmacology, vol. 130, no. 2, pp. 354-362, 2010.

[16] N. Iizuka, K. Miyamoto, K. Okita et al., "Inhibitory effect of Coptidis Rhizoma and berberine on the proliferation of human esophageal cancer cell lines," Cancer Letters, vol. 148, no. 1, pp. 19-25, 2000.

[17] J. Jin, P. Zhao, and F. Li, "The effect of $\mathrm{pH}$ on the MIC of Terminilia chebula Retz. to bacteria," Nei Mongol Journal of Traditional Chinese Medicine, vol. 8, pp. 52-55, 2008.

[18] W. Liu, J. H. Tang, L. W. Zhou, L. Liu, and M. Ding, “The bacteriostatic action and ultrastructure of myrobalan," Jiangsu Agricultural Sciences, vol. 42, no. 6, pp. 281-283, 2014.

[19] X. Zhi, E. Cui, Y. Fan et al., "In vitro antibacterial activities of fourteen traditional Chinese medicines and their compounds," Acta Agriculturae Boreali-Occidentalis Sinica, vol. 23, no. 7, pp. 114-119, 2014.

[20] Y. Ye, X. Huang, Y. Zhang et al., "Calcium influx blocked by SK\&F 96365 modulates the LPS plus IFN- $\gamma$-induced inflammatory response in murine peritoneal macrophages," International Immunopharmacology, vol. 12, no. 2, pp. 384-393, 2012.

[21] G. Wang, B. Yu, Y. Wu, B. Huang, Y. Yuan, and C. S. Liu, "Controlled preparation and antitumor efficacy of vitamin E TPGS-functionalized PLGA nanoparticles for delivery of paclitaxel," International Journal of Pharmaceutics, vol. 446, no. 1-2, pp. 24-33, 2013.

[22] W. Chen, W. Zhang, W. Shen, and K. Wang, "Effects of the acid polysaccharide fraction isolated from a cultivated Cordyceps sinensis on macrophages in vitro," Cellular Immunology, vol. 262, no. 1, pp. 69-74, 2010.

[23] L. C. Green, D. A. Wagner, J. Glogowski, P. L. Skipper, J. S. Wishnok, and S. R. Tannenbaum, "Analysis of nitrate, nitrite, and $\left[{ }^{15} \mathrm{~N}\right]$ nitrate in biological fluids," Analytical Biochemistry, vol. 126, no. 1, pp. 131-138, 1982.

[24] M. F. Otuki, F. Vieira-Lima, Â. Malheiros, R. A. Yunes, and J. B. Calixto, "Topical antiinflammatory effects of the ether extract from Protium kleinii and $\alpha$-amyrin pentacyclic triterpene," European Journal of Pharmacology, vol. 507, no. 1-3-, pp. 253259, 2005.

[25] L. E. Wise, R. Cannavacciulo, B. F. Cravatt, B. F. Martin, and A. H. Lichtman, "Evaluation of fatty acid amides in the carrageenan-induced paw edema model," Neuropharmacology, vol. 54, no. 1, pp. 181-188, 2008.

[26] D. A. Hume, "The mononuclear phagocyte system," Current Opinion in Immunology, vol. 18, no. 1, pp. 49-53, 2006. 
[27] S. H. Lee, E. Soyoola, P. Chanmugam et al., "Selective expression of mitogen-inducible cyclooxygenase in macrophages stimulated with lipopolysaccharide," The Journal of Biological Chemistry, vol. 267, no. 36, pp. 25934-25938, 1992.

[28] H. J. Lee, E.-A. Hyun, W. J. Yoon et al., "In vitro antiinflammatory and anti-oxidative effects of Cinnamomum camphora extracts," Journal of Ethnopharmacology, vol. 103, no. 2, pp. 208-216, 2006.

[29] X. F. Niu, Q. L. Mu, W. F. Li, H. Yao, H. N. Li, and H. M. Huang, "Esculentic acid, a novel and selective COX-2 inhibitor with anti-inflammatory effect in vivo and in vitro," European Journal of Pharmacology, vol. 740, pp. 532-538, 2014.

[30] S. V. Popov, G. Y. Popova, R. G. Ovodova, O. A. Bushneva, and Y. S. Ovodov, "Effects of polysaccharides from Silene vulgaris on phagocytes," International Journal of Immunopharmacology, vol. 21, no. 9, pp. 617-624, 1999.

[31] J.-R. Chen, Z.-Q. Yang, T.-J. Hu et al., "Immunomodulatory activity in vitro and in vivo of polysaccharide from Potentilla anserina," Fitoterapia, vol. 81, no. 8, pp. 1117-1124, 2010.

[32] L. Jiao, D. Wan, X. Zhang, B. Li, H. Zhao, and S. Liu, "Characterization and immunostimulating effects on murine peritoneal macrophages of oligosaccharide isolated from Panax ginseng C.A. Meyer," Journal of Ethnopharmacology, vol. 144, no. 3, pp. 490-496, 2012.

[33] T. Mattiello, G. Fiore, E. R. Brown, M. D’Ischia, and A. Palumbo, "Nitric oxide mediates the glutamate-dependent pathway for neurotransmission in Sepia officinalis chromatophore organs," The Journal of Biological Chemistry, vol. 285, no. 31, pp. 2415424163, 2010.

[34] M. J. Rebelo, C. Sousa, P. Valentão, R. Rego, and P. B. Andrade, "Phenolic profile of Douro wines and evaluation of their NO scavenging capacity in LPS-stimulated RAW 264.7 macrophages," Food Chemistry, vol. 163, pp. 16-22, 2014.

[35] H. Ye, W. Wu, Z. Liu et al., "Bioactivity-guided isolation of antiinflammation flavonoids from the stems of Millettia dielsiana Harms," Fitoterapia, vol. 95, pp. 154-159, 2014.

[36] W. L. Chul, M. P. Sang, S. K. Youn et al., "Biomolecular evidence of anti-inflammatory effects by Clematis mandshurica Ruprecht root extract in rodent cells," Journal of Ethnopharmacology, vol. 155, pp. 1141-1155, 2014.

[37] B. B. Aggarwal, S. C. Gupta, and B. Sung, "Curcumin: an orally bioavailable blocker of TNF and other pro-inflammatory biomarkers," British Journal of Pharmacology, vol. 169, no. 8, pp. 1672-1692, 2013.

[38] E. A. V. Moelants, A. Mortier, J. van Damme, and P. Proost, "Regulation of TNF- $\alpha$ with a focus on rheumatoid arthritis," Immunology \& Cell Biology, vol. 91, no. 6, pp. 393-401, 2013.

[39] H. Hosseinzadeh, M. H. Haddadkhodaparast, and A. R. Arash, "Antinociceptive, antiinflammatory and acute toxicity effects of Salvia leriifolia benth. Seed extract in mice and rats," Phytotherapy Research, vol. 17, no. 4, pp. 422-425, 2003.

[40] M. Di Rosa, "Biological properties of carrageenan," Journal of Pharmacy and Pharmacology, vol. 24, no. 2, pp. 89-102, 1972.

[41] G. Q. Zhang, X. D. Huang, H. Wang et al., "Anti-inflammatory and analgesic effects of the ethanol extract of Rosa multiflora Thunb. hips," Journal of Ethnopharmacology, vol. 118, no. 2, pp. 290-294, 2008. 


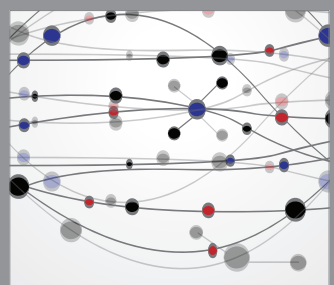

The Scientific World Journal
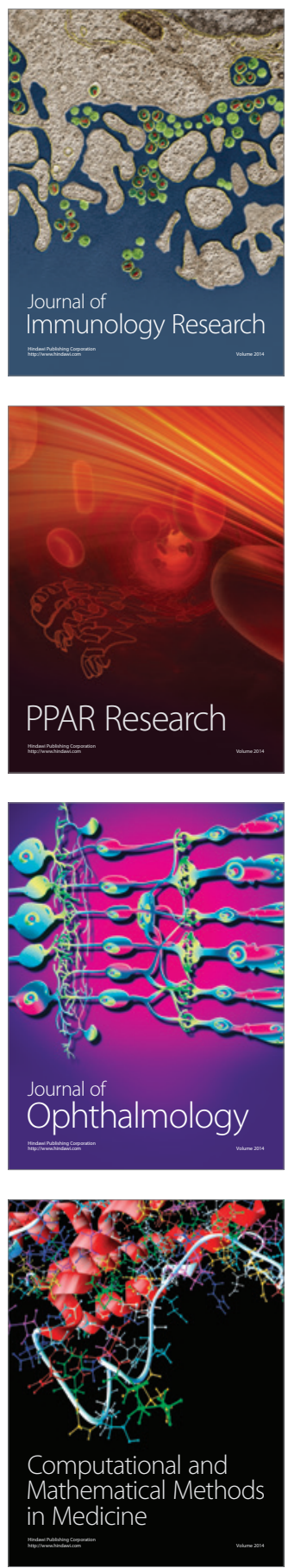

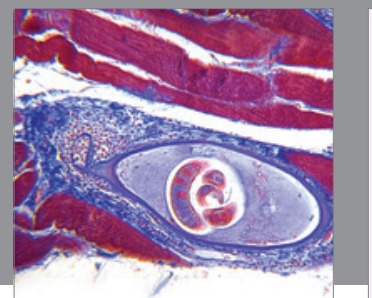

Gastroenterology

Research and Practice
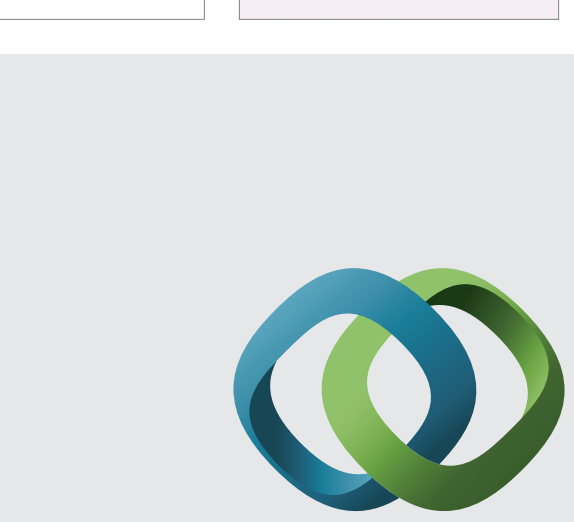

\section{Hindawi}

Submit your manuscripts at

http://www.hindawi.com
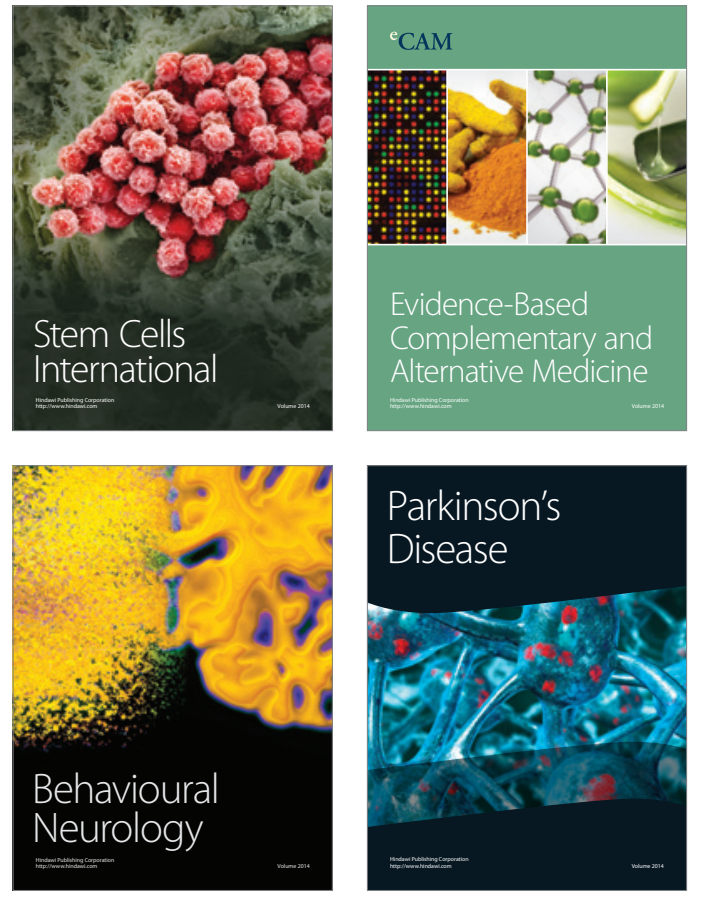
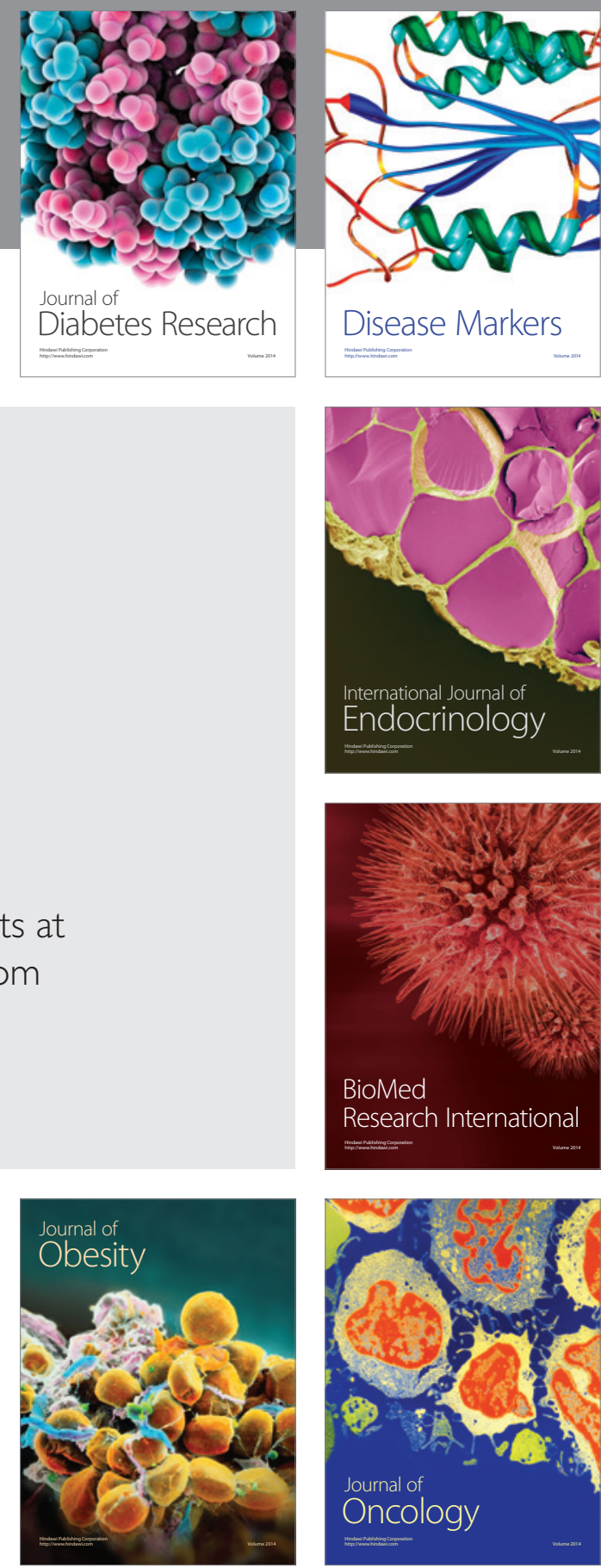

Disease Markers
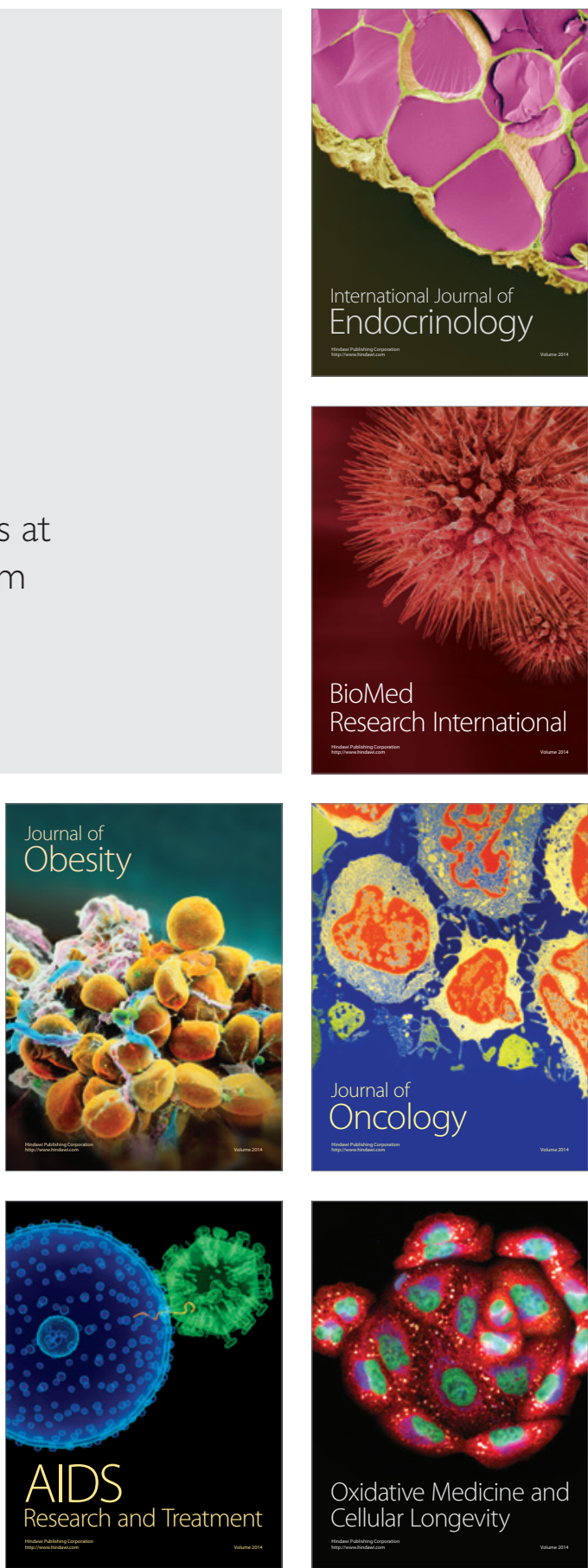